\title{
The Study on the influence of the hull deformation on the lateral vibration of the shaft system of different inner shaft
}

\author{
Wang Yanwen ${ }^{1, a}$, Chen Jiahui ${ }^{1, b}$, Gai $\operatorname{shan}^{1, c}$ \\ 1 Wuhan University of Technology, Wuhan, China \\ awangyanwenwhut@163.com, bjh123@163.com, c gaishan@163.com
}

Keywords: hull deformation; modal analysis; lateral vibration; natural frequency.

Abstract. in order to ensure the normal operation of the ship propulsion system and ship navigation, this paper analyzes the deformation of a bulk carrier with workbench by means of finite element analysis. The relative displacement of the bearings under different working conditions is calculated, and the relationship between the natural frequency of the ship's deformation and the lateral vibration is obtained by the modal analysis. The results show that the natural frequency of transverse vibration of the same inner diameter shaft is increased gradually in the condition of the ship's sitting, floating and full load. Under the same working condition, the natural frequency of the transverse vibration natural frequency of the shaft is gradually reduced. Therefore, in the same or different working conditions, the ship hull deformation has a great influence on the natural frequency of the different diameter and the same inner diameter of the shaft system.

\section{Introduction}

Use italic for emphasizing a word or phrase. Do not use boldface typing or capital letters except for section headings (cf. remarks on section headings, below). Marine propulsion shaft connected to the hull by a bearing - bearing housing, position changes will directly affect the bearing shaft transverse vibrations of natural frequency. Since the draft state under different boat experience different degrees of large deformation causes a change in the relative position of the bearing [1,2]. With the main engine power increasing, the shaft stiffness gradually become larger, especially for stern model ship, its stubby shaft makes the shaft stiffness become larger, small changes in the vertical position of the bearing base will make shafting transverse vibration have a greater impact [3]. With the development of large-scale ship, different inner diameter of ship shaft will also affect the natural frequency of the shaft lateral vibration. Therefore, the research ship hull deformation under different conditions on different Canon shaft lateral vibration, to ensure normal operation of the ship propulsion shafting and security of navigation is of great significance.

The study of domestic and foreign scholars on the shaft vibration, mostly based on the centerline of the shaft and bearing parallel and on a horizontal straight line, regardless of hull deformation of [4-6], there are a few to consider the deformation of the hull, but It does not take into account changes in the internal diameter of the shaft, which is inconsistent with the actual situation of large ship shaft. Therefore, the article take a dock for bulk carriers, floating and full load conditions, the finite element analysis workbench for a bulk carrier hull deformation finite element simulation study, obtained under different conditions shafting relative displacement of each bearing were established in the workbench software ship at dock sitting, floating and full load of shaft model, modal analysis, hull deformation obtained with different Canon lateral shaft vibration natural frequency.

\section{Finite element model of ship hull}

The hull of Ship will have deformation in the case of in dock, full load and floating, It affects the natural frequency of transverse vibration of shafting. The relative position of the bearing is needed to analysis the shafting vibration frequency., And not the entire hull. According to the influence degree of each ship cabin on the shaft, considering only the stern cabin, cabin and cargo on the shafting vibration influence, other class does not need to consider, the precision is enough. The research 
object is a large bulk cargo ship, the main parameters of the bulk cargo ship: length of $88.916 \mathrm{~m}$, designed waterline length $86.4 \mathrm{~m}, 16.5 \mathrm{~m}$ type wide, deep $7.4 \mathrm{M}$, draft $5.7 \mathrm{~m}$. and set up the finite element model of the "stern cabin - room - hold" as shown in Figure 1.

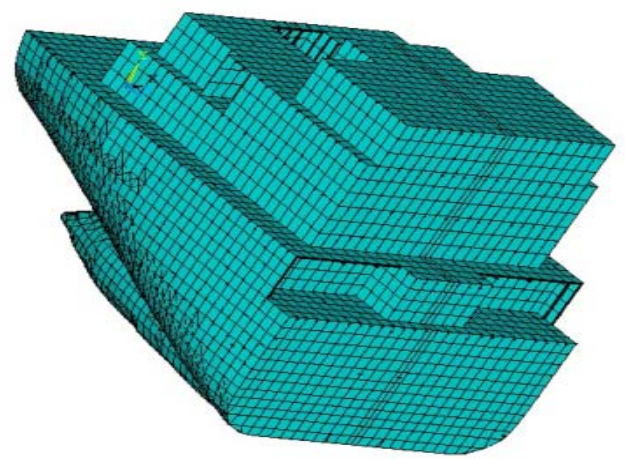

Fig 1 .stern cabin - room - cargo finite element model

Under the condition of drift and full load, the simulation of hull deformation is carried out, and all the mechanical weight of the ship is applied to the corresponding position of the ship in the form of uniform load. The pressure of the center of the unit is the average pressure of the whole unit, and the load of the goods and water on the deck and the bottom plate are respectively in the form of the average pressure. In the modal analysis, in order to prevent the rigid displacement of the ship, the front transverse bulkhead of the cabin has been full constrainted, ignoring the wave of the thrust, propeller thrust and the role of water power. The finite element model of the ship under full load is shown in Figure 2.

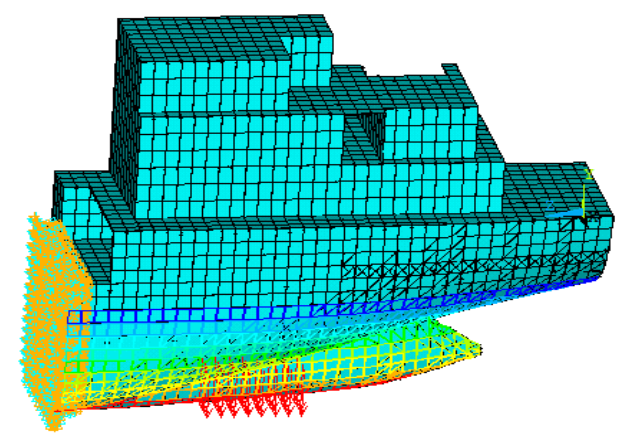

Fig. 2 finite element model of ship's full load condition

\section{Calculation results of ship hull deformation at bearing}

The bearing of ship shaft is composed by stern bearing, front stern bearing and gear box bearing. Because of the influence of ship deformation on the lateral displacement of the bearing is very small, Only considering the vertical displacement of shaft. The front stern bearing as the reference point which can obtain relative displacement stern bearing, gear box bearing and front stern bearing, then the absolute deformation is obtained, as shown in Table 1 . The absolute deformation and relative deformation of the shaft are shown in Figure 3 and Figure 4.

Table 1 the hull deformation on the bearing

\begin{tabular}{|c|c|c|c|c|}
\hline \multirow{2}{*}{ Bearing name } & \multicolumn{2}{|c|}{ Full load condition } & \multicolumn{2}{c|}{ idle condition } \\
\cline { 2 - 5 } & $\begin{array}{c}\text { absolute } \\
\text { displacement } / \mathrm{mm}\end{array}$ & $\begin{array}{c}\text { relative } \\
\text { displacement } / \mathrm{mm}\end{array}$ & $\begin{array}{c}\text { absolute } \\
\text { displacement /mm }\end{array}$ & $\begin{array}{c}\text { relative } \\
\text { displacement /mm }\end{array}$ \\
\hline $\begin{array}{c}\text { After the stern } \\
\text { bearing }\end{array}$ & 6.776 & 0.46 & 2.1271 & 0.1124 \\
\hline The stern & 6.316 & 0 & 2.0157 & 0 \\
\hline
\end{tabular}




\begin{tabular}{|c|c|c|c|c|}
\hline bearing & & & & \\
\hline $\begin{array}{c}\text { Gear box } \\
\text { bearing }\end{array}$ & 5.8789 & -0.3352 & 2.1780 & 0.1633 \\
\hline
\end{tabular}

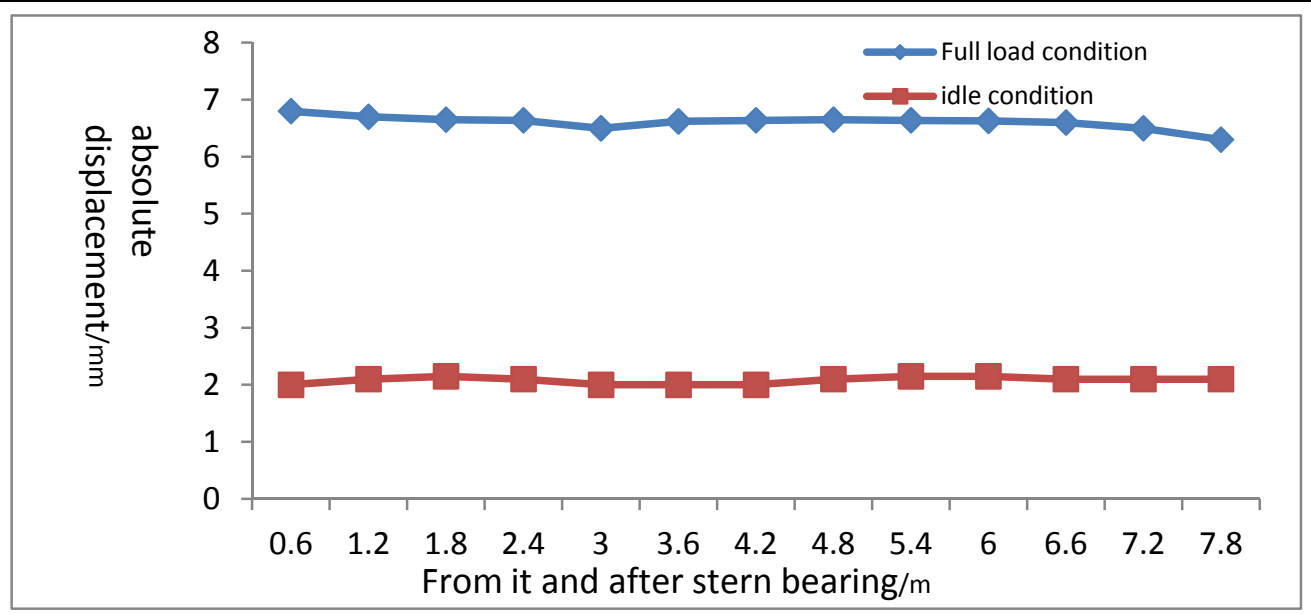

Fig. 3 vertical deformation of shaft system

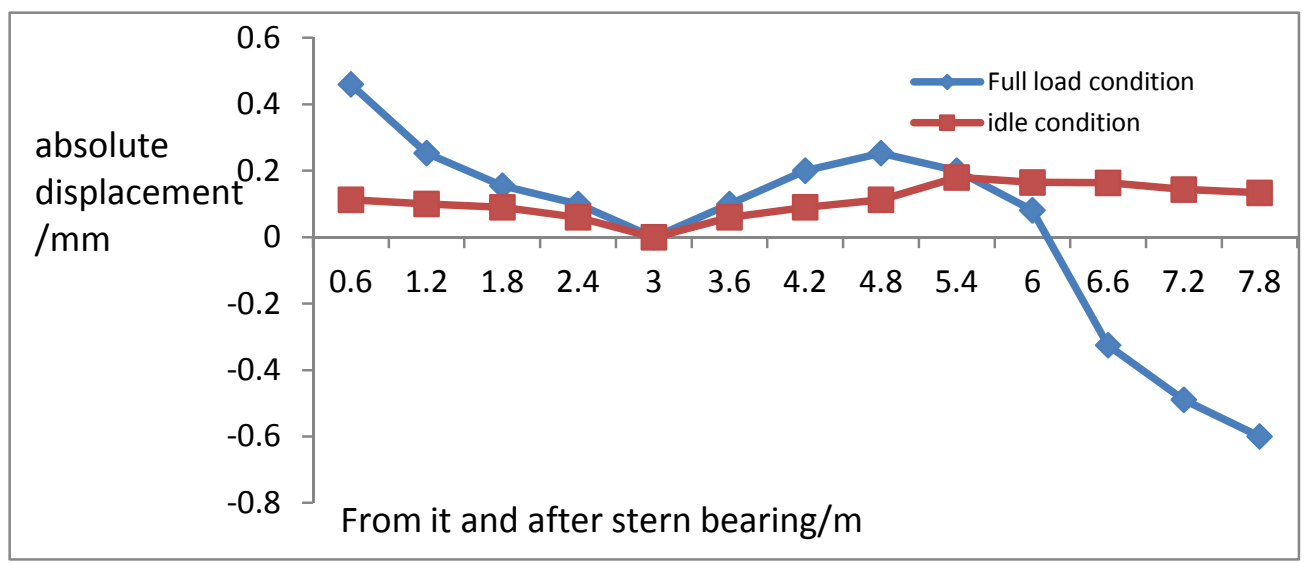

Fig. 4 vertical relative deformation of shaft

From table 1, figure 3 and figure 4 can be seen, the shaft has large deformation under full load condition and axial deformation is more obvious. The largest absolute deformation occurred at stern bearing and reaches $6.776 \mathrm{~mm}$. Under the no-load condition, the change of the axial line is relatively flat and the largest absolute deformation which be occurred in the gear box bearing reaches $2.1780 \mathrm{~mm}$. This is in line with the actual situation. Under the full load, due to the effect of propeller hydrodynamic, working conditions of stern bearing are very harsh and its deformation will increase which has a great impact on the effective contact length of stern bearing. Under the no-load condition, because of the gravity of main engine led to the deformation of gear box bearing is very large. From the above analysis, we can see that the full load condition is the biggest influence on the vibration of shafting.

\section{Calculation and analysis of shafting vibration}

The finite element model of article is established in workbench and will adopt the following principles:

(1) The propeller is simplified as a disc and it will obey the Law of conservation of mass and the Conservation law of moment of inertia.

(2) The flange and the shaft coupling of shafting will be appropriate amplification . the purpose is to ensure the connections strength and stiffness remain unchanged. 
(3) Each bearing in shafting will be simulated with three equal strength and equal stiffness of the spring

The ship in the docking condition, basically in a straight shaft, axis deformation is very small, there will be no research

model of shafting were established in ship floating and full load conditions, which Refer to figure Axis vertical relative deformation data and then solve The natural frequency of transverse vibration of shafting when ship was in the condition of full load and no-load.

The parameters of the ship shafting as below; The propeller diameter is $1705 \mathrm{~mm}$, The propellers weight is $2613 \mathrm{~kg}$, The axial length is $8.512 \mathrm{~m}$ : shafts external diameter is $380 \mathrm{~mm}$. the linear model of shafting In the finite element state as shown in Figure 5. Because the size of the inner diameter is less than0.4 times the external diameter . so This article will take the hift diameter was $0,50,70,90120 \mathrm{~mm}$ as the research object,and then calculating the natural frequency of transverse vibration of shafting as shown in Table 2.

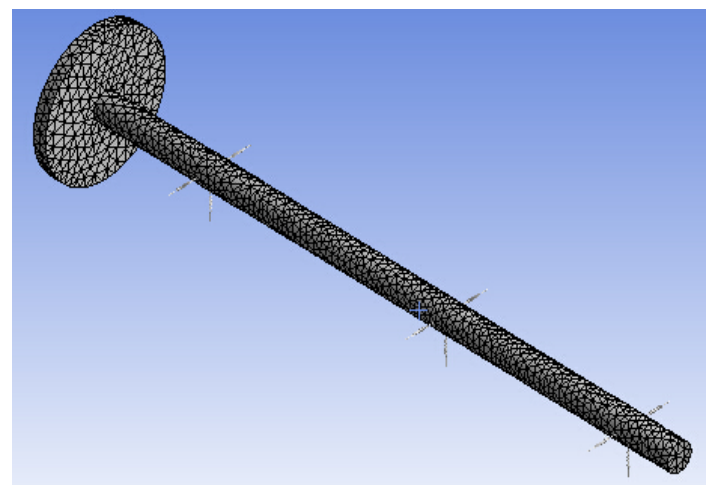

Fig. 5 finite element model of a bulk ship shafting

Table 2 natural frequency of shaft vibration

\begin{tabular}{|c|c|c|c|c|c|c|}
\hline \multirow{2}{*}{$\begin{array}{c}\text { Ship } \\
\text { condition }\end{array}$} & \multirow{2}{*}{$\begin{array}{c}\text { Shaft } \\
\text { diameter } / \mathrm{mm}\end{array}$} & \multicolumn{5}{|c|}{ natural frequency /HZ } \\
\cline { 2 - 6 } & 0 & 1 order & 2 order & 3 order & 4 order & 5 order \\
\cline { 2 - 6 } & 50 & 24.067 & 54.457 & 62.799 & 75.022 & 129.410 \\
\cline { 2 - 6 } Floating \\
condition & 70 & 21.875 & 50.369 & 60.325 & 71.012 & 124.023 \\
\cline { 2 - 6 } & 90 & 18.231 & 45.689 & 55.567 & 68.065 & 115.446 \\
\cline { 2 - 6 } & 120 & 16.356 & 30.155 & 52.458 & 66.245 & 111.012 \\
\hline \multirow{3}{*}{$\begin{array}{c}\text { Full load } \\
\text { condition }\end{array}$} & 0 & 48.216 & 100.56 & 119.07 & 202.53 & 247.06 \\
\cline { 2 - 6 } & 50 & 45.834 & 95.482 & 110.752 & 190.752 & 231.452 \\
\cline { 2 - 6 } & 70 & 42.785 & 92.354 & 105.159 & 184.627 & 225.014 \\
\cline { 2 - 6 } & 90 & 40.424 & 87.186 & 98.429 & 176.045 & 214.301 \\
\hline
\end{tabular}

We can get from the above results that Shafting natural frequency of transverse vibration have different values, and These values vary greatly. the shafting natural frequency of transverse vibration of full load is much larger than the floating condition in a same internal diameter . in one working condition ,With the increase of the diameter of the shaft, the natural frequency of the same order of shafting transverse vibration decreases gradually. In order to ensure the normal operation of ship propulsion shafting and the safety of the sail, when the ship started The excitation frequency must quickly through the natural frequency of transverse vibration, to avoid the occurrence of resonance.

\section{Conclusion}

Through the above research, the natural frequency of transverse vibration of the shafting hull deformation with different diameters are quite different 
(1) Account to various parameters of the ship,the modal analysis in the workbench module calculation of hull deformation in shaft system of shaft deformation measuring tool has a certain authenticity.

(2) In consideration of ship deformation, research on shafting vibration of domestic and foreign scholars, most without considering the deformation of the different natural frequency of shaft lateral vibration impact, and Research on the most solid shaft is limited. The purpose of this paper is to find out the influence of different deformation on the natural frequency of transverse vibration of shafting. (3) The influence of natural frequency of transverse vibration of different diameter shaft in ship hull deformation as follows; On the deformation of the ship to certain circumstance,whether it is under full load condion or light load conditions, the natural frequency of transverse vibration of the crankshaft decreases with increasing the diameter of the shaft, and the decrease amplitude is not very big.

(4) Hull deformation effect on the natural frequency of transverse vibration in shaft system of rules can help ship designers better according to the ship parameters are chosen properly, the inner diameter of the shaft, to ensure the operation of the ship can well avoid or fast through the resonance region, to ensure the safety of navigation of the ship.

(5) This article just select several representative diameter shaft system experiment,lacking continuous diameter shaft system experiment,and the actual situation to a certain difference,need further research.

\section{References}

[1]Lech Murawski. Shaft line alignment analysis taking ship construction flexibility and deformation into consideration [J]. Marine Structures, 2005, 18(1): 62-84.

[2] Dong Hengjian, Zhang Jianjun. Study on the influence of hull deformation on shafting alignment [J]. ship engineering, 2009, 31 (Z1): 8-11.

[3]Schulten. P. The interaction between diesel engines, ship and propellers during manoevring[D]. Delft University Press, 2005.

[4] Zhou Chunliang. Study on vibration of ship shafting [D]. Harbin: Harbin Engineering University, 2006

[5] J Jenzer. Some Vibration Aspects of Modern Ship Installations [M]. Winterthur: Wartsila NSD Switzerland Ltd, 1997.

[6] Zhou Chunliang, Liu Zhansheng, Zheng Hongtao. Influence of bearing length and spacing on vibration characteristics of ship shafting [J]. ship engineering, 2007, 29 (5): 16-18.

[7] Chinese veritas. Steel ships into standardized [S]. Beijing: China Communications Press, 2009 